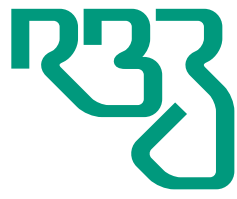

\section{Revista}

Brasileira de

Zootecnia

Brazilian Journal of Animal Science

ISSN 1806-9290

www.rbz.org.br

\title{
Effect of immunocastration on sex glands of male Mangulica (Swallow-bellied Mangalitsa) pigs
}

\author{
Marija Gogić $^{1}$ (iD), Čedomir Radović ${ }^{1}$ (D), Marjeta Čandek-Potokar ${ }^{2}$ (iD, \\ Milica Petrović $^{3}$ (D), Dragan Radojković ${ }^{3}$ (ID, Nenad Parunović ${ }^{4}$ (D), \\ Radomir Savić ${ }^{3^{*}}$ \\ ${ }^{1}$ Institute for Animal Husbandry, Belgrade-Zemun, Serbia. \\ 2 Agricultural Institute of Slovenia, Ljubljana, Slovenia. \\ ${ }^{3}$ University of Belgrade, Faculty of Agriculture, Belgrade-Zemun, Serbia. \\ ${ }^{4}$ Institute of Meat Hygiene and Technology, Belgrade, Serbia.
}

\author{
*Corresponding author: \\ savic@agrif.bg.ac.rs \\ Received: December 6, 2018 \\ Accepted: April 7, 2019 \\ How to cite: Gogić, M.; Radović, Č.; Čandek- \\ Potokar, M.; Petrović, M.; Radojković, D.; \\ Parunović, N. and Savić, R. 2019. Effect of \\ immunocastration on sex glands of male \\ Mangulica (Swallow-bellied Mangalitsa) pigs. \\ Revista Brasileira de Zootecnia 48:e20180286. \\ https://doi.org/10.1590/rbz4820180286 \\ Copyright: This is an open access article \\ distributed under the terms of the \\ Creative Commons Attribution License \\ (http://creativecommons.org/licenses/by/4.0/) \\ which permits unrestricted use, distribution, \\ and reproduction in any medium, provided the \\ original work is properly cited.
}

\begin{abstract}
The objective of this research was to study the effect of immunocastration on the morphometric characteristics of sex glands in male Swallow-bellied Mangalitsa pigs. The study included 24 animals (13 entire and 11 immunocastrated males). The research focused on the following traits: age at slaughter (days), live weight at slaughter $(\mathrm{kg})$, growth rate $\left(\mathrm{kg} \mathrm{day}^{-1}\right)$, and morphometric testicle traits (volume, $\mathrm{cm}^{3}$; weight, g; length, width, thickness, and circumference, $\mathrm{mm}$ ). The efficacy of immunocastration was determined based on androstenone and skatole levels in adipose tissue. The group of immunocastrated animals had higher body weight at slaughter $(+18.8 \mathrm{~kg})$ due to higher average daily live gain $(+87 \mathrm{~g})$. Immunocastration resulted in reduced morphometric measures of testes. The volumes and weight of testes/epididymes were reduced by 28.9-54.4 and 32.1-53.3\%, respectively. Testis length and other size-related traits were significantly reduced by $17.4-27.6 \%$. The linear regression effect of live body weight at slaughter within the immunocastrated group on testis measurements was not significant. Within the entire group of males, the increase of live body weight at slaughter by $1 \mathrm{~kg}$ had an effect on the increase of volume and weight of testes/epididymes by $0.55-2.24 \mathrm{~cm}^{3}$ and $0.52-2.28 \mathrm{~g}$, respectively. Other size-related testis traits increased by $0.04-0.55 \mathrm{~mm}$ for each $\mathrm{kg}$ of body weight. Immunocastration also resulted in $79.6 \%$ decrease in the weight of accessory sex glands. The present study is the first to demonstrate that immunocastration could be a method of choice for castration of the local fatty pig breed, Mangulica (Swallow-bellied Mangalitsa).
\end{abstract}

Keywords: androstenone, entire males, immunocastrated males, skatole, testis size

\section{Introduction}

In view of the voluntary end of piglet castration in the European Union, interest in research on immunocastration, as an alternative to surgical castration of male pigs, has increased. Immunocastration by vaccination immunologically blocks the signal from gonadotropin-releasing hormone (GnRH), thus decreasing the secretion of luteinising hormone ( $\mathrm{LH}$ ), follicle-stimulating hormone (FSH), and testicular steroids (Čandek-Potokar et al., 2017). For effective immunisation, two applications of vaccine are needed within (at least) a four-week interval, and the vaccine manufacturer recommends a delay of four to six weeks before slaughter for the clearance of boar taint substances. Due to immunisation, levels of substances responsible for boar taint (androstenone and skatole) are reduced. 
Immunocastration also results in regression of testes and accessory sex glands compared with entire males (Batorek et al., 2012a), with early immunisation provoking more substantial reductions (Brunius, 2011). Research results using computed tomography suggested that the volume ratio between testes and body of entire males is a good parameter to assess the effectiveness of immunocastration (Font-i-Furnols et al., 2016). Other studies (Bonneau, 2010; Čandek-Potokar et al., 2014) suggested that the weight of accessory sex glands, in particular the seminal vesicle, is a more reliable indicator for the on-line assessment of effective immunocastration.

In the case of a longer life cycle, which is more usual in local or autochthonous breeds of pigs than in commercial, fattening pigs, the standard vaccination protocol recommended by the vaccine manufacturer may have to be adapted. In that respect, the vaccine manufacturer recommends a third application of the vaccine; however, this may not always be applicable in practical conditions (e.g. outdoor rearing systems). For Iberian pigs scheduled for the montanera production system, an adaptation of the vaccination protocol was developed (Hernández-García et al., 2013). However, the success rate of this protocol was lower for entire males (not females), which the authors ascribed to differences in nutritional status and stress (Hernández-García et al., 2018).

Generally, there is a lack of information about the results of immunocastration in local pig breeds that are held in special production systems and reared for a longer time than usual. Mangulica is a fatty-type breed with slower growth and older age at the start of fattening compared with conventional pigs; therefore, the vaccination protocol should be adapted. The objective of this research was, thus, to study the effect of immunocastration on the morphometric characteristics of reproductive organs in Mangulica (Swallow-bellied Mangalitsa) pigs, an autochthonous Serbian breed.

\section{Material and Methods}

The study was conducted in the facilities (on a pig farm and in the slaughterhouse) of a research

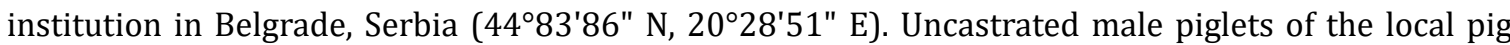
breed Mangulica (Swallow-bellied Mangalitsa) were purchased from several breeding farms and delivered to the research farm immediately after weaning. During the period from weaning to the start of the trial, all the male piglets were raised in the same housing conditions and received the same diet. At about $27 \mathrm{~kg}$ live weight and 173 days of age, the pigs were assigned to one of two experimental groups, entire male or immunocastrated, with 13 and 11 pigs, respectively. One animal in the entire male group and one in the immunocastrated group came from the same litter. The study lasted from March to August. The animals were kept in their experimental groups in two separate enclosures with access to outdoor areas (i.e. each enclosure had both a covered and an outdoor area). Each enclosure had a surface area of $150 \mathrm{~m}^{2}$ ( $40 \mathrm{~m}^{2}$ of covered area and $110 \mathrm{~m}^{2}$ of outdoor area). During the trial, the animals were fed two complete feed mixtures (Table 1). Pigs had free access to water and were fed throughout the study an average of 2.14 and $2.36 \mathrm{~kg} \mathrm{day}^{-1}$ of complete mixture per animal in the entire

Table 1 - Composition of feed mixtures

\begin{tabular}{lcc}
\hline Ingredient $\left(\mathrm{g} \mathrm{kg}^{-1}\right)$ & Mixture $1(25-60 \mathrm{~kg})$ & Mixture 2 $(60-100 \mathrm{~kg})$ \\
\hline Corn (dry) & 632.7 & 691.5 \\
Wheat flour & 150.0 & 150.0 \\
Soybean meal & 139.0 & 90.0 \\
Sunflower meal & 50.0 & 40.0 \\
Calcium carbonate & 10.0 & 9.0 \\
Dicalcium & 9.0 & 10.0 \\
Salt & 4.3 & 4.5 \\
Premix & 5.0 & 5.0 \\
ME $\left(\mathrm{MJ} \mathrm{kg}^{-1}\right)$ & 13.6 & 13.5 \\
Protein $\left(\mathrm{g} \mathrm{kg}^{-1}\right)$ & 147 & 130 \\
Lysine $\left(\mathrm{g} \mathrm{kg}^{-1}\right)$ & 6.6 & 5.5
\end{tabular}


male and immunocastrated groups, respectively. Pigs were weighed once a month. At the same time, the amount of feed intake at group level was also recorded. The average daily gain individually for each pig (kg) and feed conversion ratio at group level (average daily feed intake/average daily growth, $\mathrm{kg} \mathrm{kg}^{-1}$ ) were calculated.

As the study involved use of a vaccine that is not yet registered in Serbia, the approval of the study by the Ethical Council for Welfare of Experimental Animals was obtained from the Veterinary Directorate (case no. 323-07-10545/2015-05/2).

Immunocastration was performed using Improvac ${ }^{\circledR}$ vaccine according to the manufacturer's recommendation, i.e. two applications. However, considering that Mangulica pigs were older at the start of the trial, as is common with conventional pigs, the vaccination protocol was adapted, i.e. first vaccination was conducted at 85 days (at about $78 \mathrm{~kg}$ live weight) and the second 40 days prior to slaughter (at about $100 \mathrm{~kg}$ live weight).

At the age of 360 days (live weight of about 100 and $120 \mathrm{~kg}$ for entire males and immunocastrated group, respectively), the pigs were transported to the experimental slaughterhouse. At evisceration, selected reproductive organs were collected for further dissection.

The research encompassed the following traits: age at slaughter (days), live weight at slaughter (kg), daily live weight gain $\left(\mathrm{kg} \mathrm{day}^{-1}\right)$, feed conversion ratio $\left(\mathrm{kg} \mathrm{kg}^{-1}\right)$, total volume of testes $\left(\mathrm{cm}^{3}\right)$, volume of testes without epididymes $\left(\mathrm{cm}^{3}\right)$, volume of epididymes $\left(\mathrm{cm}^{3}\right)$, total weight of testes $(\mathrm{g})$, weight of testes without epididymes $(\mathrm{g})$, weight of epididymes $(\mathrm{g})$, total length of testes $(\mathrm{mm})$, length of testes without epididymes $(\mathrm{mm})$, width of testes $(\mathrm{mm})$, thickness of testes with epididymes $(\mathrm{mm})$, circumference of testes without epididymes (mm), and weight of accessory sex glands (g).

Separate morphological measurements were performed for left and right testis/epididymis. We measured their length, width, and thickness by using a slide gauge meter, the circumference of testes with a measuring tape, the volume of testes with a volumetric jar by the water displacement method, and the weight of reproductive organs by using digital scales with $\pm 0.1 \mathrm{~g}$ accuracy.

The efficacy of immunocastration was determined based on the levels of androstenone (limit of detection $0.24 \mu \mathrm{g} \mathrm{g}^{-1}$ ) and skatole (limit of detection $0.03 \mu \mathrm{g} \mathrm{g}^{-1}$ ) in adipose tissue. The samples of subcutaneous adipose tissue (50 g) were taken at the level of the last rib. Levels of androstenone and skatole were determined by the HPLC method as described by Batorek et al. (2012b). Briefly, adipose tissues were microwaved to extract liquid fat, which was centrifuged, warmed to a suitable temperature, and spiked with known amounts of androstenone and 2-methylindole. After ultrasonication and cooling, spiked fat was re-centrifuged. For determination of androstenone, $50 \mu \mathrm{L}$ of supernatant were exposed to derivatisation with dansyl hydrazine for exactly $2 \mathrm{~min}$. After that, $10 \mu \mathrm{L}$ of the mixture were injected into the HPLC column, and fluorescence was detected (excitation at $346 \mathrm{~nm}$ and emission at $521 \mathrm{~nm}$ ) using the HP 1200 HPLC system (Agilent Technologies, Waldbronn, Germany). For determination of skatole, $20 \mu \mathrm{L}$ of supernatant were injected into the HPLC column and fluorescence was detected (excitation at $285 \mathrm{~nm}$ and emission at $340 \mathrm{~nm}$ ).

Basic statistical parameters were calculated using the SAS (Statistical Analysis System, version 9.1.3) software package. Impact assessment was carried out by applying the General Linear Model procedure, using the following models:

$$
\begin{gathered}
y_{i j k}=\mu+T_{i}+S_{j}+\beta_{i}\left(x_{i j k}-\bar{x}\right)+e_{i j k} \\
y_{i j}=\mu+T_{i}+e_{i j \prime}
\end{gathered}
$$

in which $y_{i j k}$ and $y_{i j}$ are the analysed trait, $\mu$ is overall mean, $T_{i}$ is the effect of treatment (entire vs. immunocastrated males), $S_{j}$ is the effect of the side (left vs. right), $\beta_{i}\left(x_{i j k}-\bar{x}\right)$ is the linear regression effect of live weight at slaughter within the treatment, and $e_{i j \mathrm{k}}$ and $\mathrm{e}_{\mathrm{ij}}$ are random errors. The first model was used to evaluate testes and the second to assess the measurements of accessory sex glands. The 
statistical significance $(\mathrm{P}<0.05)$ of differences between means and least-squares means (LSMeans) was determined by $t$ test.

\section{Results}

Immunocastrated pigs (Table 2 ) had higher average live weight at slaughter $(+18.8 \mathrm{~kg} ; \mathrm{P}=0.041)$ due to greater average daily gain $(+87 \mathrm{~g} ; \mathrm{P}=0.009)$. During the study, immunocastrated animals consumed, on average, $0.22 \mathrm{~kg}$ of feed per day more than entire male pigs, with a better feed conversion ratio (4.85 vs. 5.21 ).

The values of determination coefficients for the analysed effect ranged from 37 to $79 \%$. Morphometric measurements of reproductive organs demonstrated no differences between left and right testis/ epididymis $(\mathrm{P}>0.05)$.

In immunocastrated pigs, immunocastration resulted in reduced morphometric measures of testes (Table 3). The volumes and weight of testes/epididymes were reduced by 28.9-54.4 and 32.1-53.3\%, respectively. Length of testes and other size-related traits were significantly reduced by $17.4-27.6 \%$.

The immunocastration treatment negatively affected the weight of accessory sex glands, a reduction of $79.6 \%$ (Table $3 ; 220.6$ vs. $45.0 \mathrm{~g}$, entire males vs. immunocastrated; $\mathrm{P}=0.006$ ). The reduction of accessory sex glands was even more pronounced than the measured reduction of testes.

The linear regression effect of live weight at slaughter within the immunocastrated group on testis measurements was not significant. Within the group of entire males, the increase of live body weight at

Table 2 - Productive performance of animals

\begin{tabular}{lccc}
\hline Trait & EM $(\mathrm{n}=13)$ & IC $(\mathrm{n}=11)$ & $\mathrm{P}$ \\
\hline Age at start of experiment (day) & $170.8 \pm 12.3$ & $176.0 \pm 10.1$ & 0.538 \\
Weight at the start of the trial (kg) & $26.3 \pm 4.2$ & $28.4 \pm 4.7$ & 0.673 \\
Age at end of experiment (day) & $357.5 \pm 25.7$ & $361.6 \pm 20.7$ & 0.864 \\
Weight at the end of the trial (kg) & $101.8 \pm 16.3$ & $120.6 \pm 24.4$ & 0.041 \\
Average daily gain during the trial (g) & $415 \pm 42$ & $502 \pm 61$ & 0.009 \\
Feed conversion ratio $\left(\mathrm{kg} \mathrm{kg}^{-1}\right)$ & $5.21 \pm 0.60$ & $4.85 \pm 0.84$ & - \\
\hline
\end{tabular}

EM - entire males; IC - immunocastrated; P - significance.

Data are means \pm SD.

Table 3 - Effect of treatment on mean morphometric traits of sex glands

\begin{tabular}{lccc}
\hline Trait & EM & IC & P \\
\hline Total volume $\left(\mathrm{cm}^{3}\right)$ & $218.6 \pm 7.9$ & $113.4 \pm 8.7$ & $<0.001$ \\
Volume of testes without the epididymes $\left(\mathrm{cm}^{3}\right)$ & $165.6 \pm 5.6$ & $75.5 \pm 6.2$ & $<0.001$ \\
Volume of epididymes $\left(\mathrm{cm}^{3}\right)$ & $53.2 \pm 2.9$ & $37.8 \pm 3.1$ & $<0.001$ \\
Total weight (g) & $231.6 \pm 8.3$ & $121.0 \pm 9.1$ & $<0.001$ \\
Weight of testes without the epididymes (g) & $170.7 \pm 5.6$ & $79.7 \pm 6.2$ & $<0.001$ \\
Weight of epididymes (g) & $60.8 \pm 3.1$ & $41.3 \pm 3.4$ & $<0.001$ \\
Total length (mm) & $124.4 \pm 2.4$ & $100.2 \pm 2.7$ & $<0.001$ \\
Length of testes without the epididymes (mm) & $91.3 \pm 1.4$ & $70.6 \pm 1.5$ & $<0.001$ \\
Width of testes (mm) & $57.9 \pm 1.2$ & $47.8 \pm 1.3$ & 0.001 \\
Thickness of testes (mm) & $51.5 \pm 1.1$ & $37.3 \pm 1.2$ & $<0.001$ \\
Circumference of testes (mm) & $162.7 \pm 3.1$ & $133.1 \pm 3.3$ & $<0.001$ \\
Weight of accessory sex glands (g) & $220.6 \pm 45.5$ & $45.0 \pm 27.4$ & 0.006 \\
\hline
\end{tabular}

EM - entire males; IC - immunocastrated; P - significance.

Data are LSMeans \pm SE. 
slaughter by $1 \mathrm{~kg}$ had an effect on the increases $(\mathrm{P}<0.001)$ of volume and weight of testes/epididymes by $0.55-2.24 \mathrm{~cm}^{3}$ and $0.52-2.28 \mathrm{~g}$, respectively. Other size-related testis traits increased $(\mathrm{P}<0.05)$ by $0.04-0.55 \mathrm{~mm}$ for each $\mathrm{kg}$ of body weight.

Of all the measurable traits on the testicles, the total testicle weight can be the most easily measured. Live weight at slaughter within group of entire males had a positive effect on the total testis weight, as estimated by linear regression analysis $(\mathrm{P}<0.001$; Figure 1$)$. Higher live body weight implies increased testis weight. Linear regression effect of live body weight within the immunocastrated group was negative $(\mathrm{P}>0.05$; Figure 2$)$.

In the samples of adipose tissue of immunocastrated pigs, the androstenone levels were below the level of detection $\left(0.24 \mu \mathrm{g} \mathrm{g}^{-1}\right.$ liquid fat), indicating the immunocastration was $100 \%$ successful. The skatole content in the adipose tissue of immunocastrated pigs ranged from 0.01 to $0.13(\overline{\mathrm{x}}=0.03) \mu \mathrm{g} \mathrm{g}^{-1}$.

\section{Discussion}

A higher average growth rate observed in immunocastrated Mangulica pigs corroborates the results generally reported in the literature for immunocastrated pigs (see meta-analysis of Batorek et al., 2012a). Faster growth of immunocastrated pigs is manifested after the second vaccination, due to the increased appetite and higher feed intake of immunocastrated pigs (Škrlep et al., 2012; Batorek et al., 2012a).

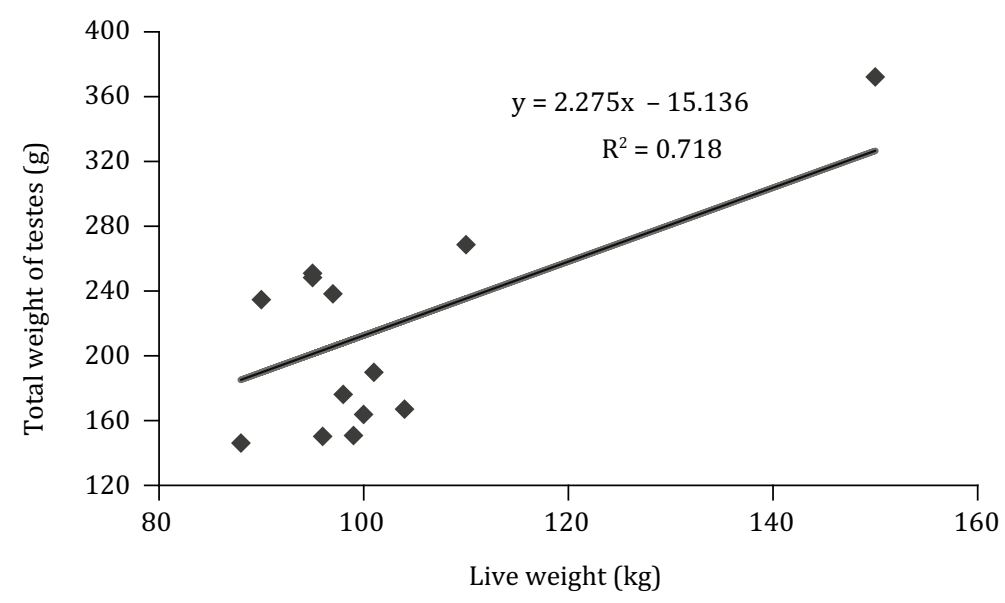

Figure 1 - Linear regression effect of live weight at slaughter on total weight of testes in the group of entire male pigs.

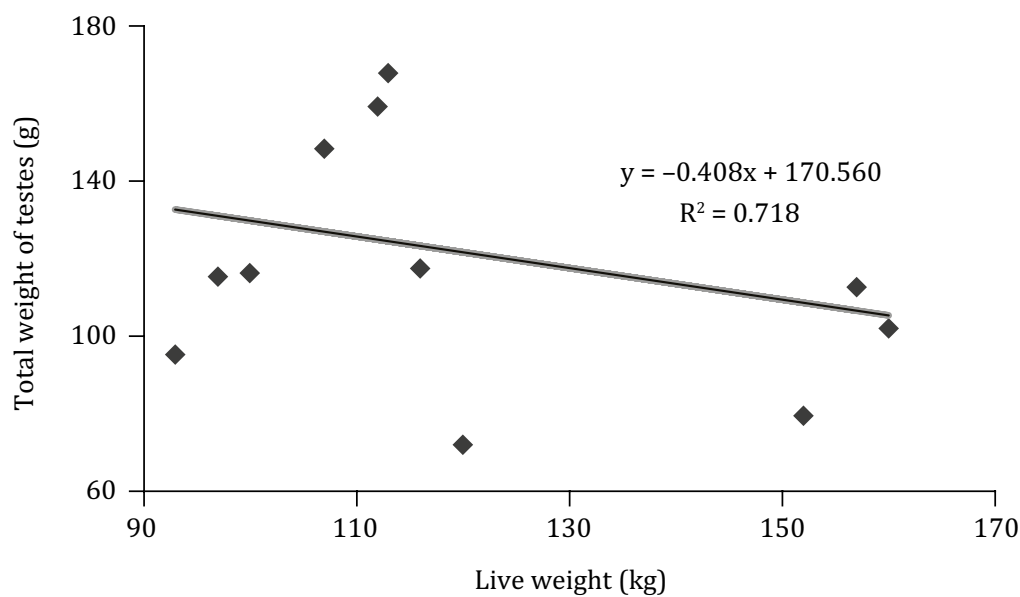

Figure 2 - Linear regression effect of live weight at slaughter on the total weight of testes in the immunocastrated group of pigs. 
Insignificant differences between morphometric traits for left and right testis are consistent with the study of Sikarwar et al. (2018), but contrary to studies that detected a bigger size of left testicle. For example, Teankum et al. (2013), examining a group of 34.6-month-old boars, determined a greater weight of left testis with epididymis than of right testis ( 546.4 and $531.5 \mathrm{~g}$, respectively). Likewise, Jacyno et al. (2015) determined greater volume of left than right testis ( 299 and $281 \mathrm{~cm}^{3}$, respectively) and greater length of left than right testis (13.8 and $13.4 \mathrm{~cm}$, respectively). In the present study on Mangulica pigs, the size of testicles in the group of entire males was smaller (the volume and weight of testicles being 13-25\%; the length and circumference being 8-20\% smaller) than recently published for pigs of modern breeds (Jacyno et al., 2015; Große-Brinkhaus et al., 2015; Lugar et al., 2017). This was regardless of the fact that our entire Mangulica males were much older (approximately one year old at slaughter), and their average body weight was similar to that of pigs in other studies (Jacyno et al., 2015; Große-Brinkhaus et al., 2015; Lugar et al., 2017). It can be speculated that their sexual development was retarded due to insufficient nutrition in prenatal and early postnatal development (Barth et al., 2008; Herring et al., 2018). There is not much information published about the effect of nutrition on sexual development of male pigs, although it has been shown that reducing ad libitum feed intake by $30 \%$ prior to puberty onset increases the age at puberty (Hughes and Varley, 1980).

The reduction of sex glands due to immunocastration in our research agrees with the results reported in the literature. Indeed, the degree of testis reduction we determined was similar to testis reductions reported in other studies (Gispert et al., 2010; Škrlep et al., 2012; Park et al., 2015; Zamaratskaia and Rasmussen, 2015). Škrlep et al. (2010) determined reductions in weight of testes (entire males:immunocastrated $=701.3: 223.2 \mathrm{~g}$ ) and epididymes (entire males:immunocastrated $=88.9: 23.6 \mathrm{~g}$ ), making reductions of 68.2 and $73.5 \%$ in testes and epididymes, respectively. A higher average degree of reduction, i.e. 7.3-fold (weight of both testes; entire males:standard immunocastrated:early immunocastrated $=539: 226: 74 \mathrm{~g}$ ) was reported in the case of so-called early immunocastration, i.e. when the immunocastration is performed at an earlier stage of development (Brunius et al., 2011).

Reduced weight of accessory sex glands by about $83.3 \%$ (entire males:immunocastrated $=304.2: 50.9 \mathrm{~g}$ ) was also determined in research by Škrlep et al. (2010). Our results correspond to the results of Bonneau (2010), who reported that the weight of seminal vesicle (vesicula seminalis) is a better criterion for testing the efficacy of immunocastration than testis size, because the size of the seminal vesicle reduces faster and to a higher degree than the size of testes. Our results corroborate literature reports summarised in the meta-analysis by Batorek et al. (2012a), which showed the greatest effect of immunocastration was measured in seminal vesicle. The effect of immunocastration on reproductive organs is dependent on the timing of effective immunocastration, as greater reduction occurs in the case of early immunocastration (Brunius, 2011).

It is worth noting that testis size was affected by live weight (significant positive regression) within the group of entire males, whereas the effect of live body weight within the immunocastrated group was insignificant. The increase in testicle size along with the increase of live body weight is in agreement with the research of Jacyno et al. (2015), who determined positive correlation between volume of testes and body weight.

Our results correspond to the results of Batorek et al. (2012b), who reported that the androstenone was at the detection limit $\left(0.24 \mu \mathrm{g} \mathrm{g}^{-1}\right)$, while skatole values were 0.03 and $0.04 \mu \mathrm{g} \mathrm{g}^{-1}$, depending on whether the nutrition of pigs was restricted or ad libitum.

As demonstrated by the meta-analysis of Batorek et al. (2012a), immunocastration reduces skatole levels, but has a substantially more important reducing effect in the case of androstenone. This is due to physiological aspects, because the vaccination has a direct effect on the reproductive axis, while its effect on skatole level is indirect. Skatole, which is not excreted through faeces, is absorbed in the blood and metabolised in the liver, and its hepatic metabolism is hindered by androstenone (Doran et al., 2002).

R. Bras. Zootec., 48:e20180286, 2019 


\section{Conclusions}

Immunocastration is efficient (as demonstrated by androstenone levels below the level of detection) and leads to reduction of all morphometric traits measured in the reproductive organs of entire males of the local pig breed, Mangulica (Swallow-bellied Mangalitsa). Greater reduction occurs in accessory sex glands than in testes. Immunocastrated Mangulica pigs demonstrate a better growth rate than entire males. The present study is the first to demonstrate that immunocastration could be a method of choice for castration applied in the fattening of local pig breed, Mangulica (Swallow-bellied Mangalitsa).

\section{Conflict of Interest}

The authors declare no conflict of interest.

\section{Author Contributions}

Conceptualization: M. Gogić, Č. Radović, M. Petrović and R. Savić. Investigation: M. Gogić, Č. Radović and R. Savić. Methodology: R. Savić. Project administration: M. Čandek-Potokar and D. Radojković. Resources: M. Gogić and Č. Radović. Supervision: M. Čandek-Potokar and R. Savić. Writing-original draft: M. Gogić, M. Čandek-Potokar and R. Savić. Writing-review \& editing: M. Gogić, Č. Radović, M. Čandek-Potokar, M. Petrović, D. Radojković, N. Parunović and R. Savić.

\section{Acknowledgments}

This project received funding from the Horizon 2020 research and innovation programme of the European Union under grant agreement No. 634476 (Project acronym: TREASURE). The content of this paper reflects only the author's view, and the European Union Agency is not responsible for any use that may be made of the information it contains. Research was also financed by the Ministry of Education, Science and Technological Development of Republic of Serbia (project TR 31081).

\section{References}

Barth, A. D.; Brito, L. F. C. and Kastelic, J. P. 2008. The effect of nutrition on sexual development of bulls. Theriogenology 70:485-494. https://doi.org/10.1016/j.theriogenology.2008.05.031

Batorek, N.; Čandek-Potokar, M.; Bonneau, M. and Van Milgen, J. 2012a. Meta-analysis of the effect of immunocastration on production performance, reproductive organs and boar taint compounds in pigs. Animal 6:1330-1338. https://doi. org/10.1017/S1751731112000146

Batorek, N.; Škrlep, M.; Prunier, A.; Louveau, I.; Noblet, J.; Bonneau, M. and Čandek-Potokar, M. 2012b. Effect of feed restriction on hormones, performance, carcass traits, and meat quality in immunocastrated pigs. Journal of Animal Science 90:4593-4603. https://doi.org/10.2527/jas.2012-5330

Bonneau, M. 2010. Accessory sex glands as a tool to measure the efficacy of immunocastration in male pigs. Animal 4:930-932. https://doi.org/10.1017/S1751731110000091

Brunius, C. 2011. Early immunocastration of male pigs-effects on physiology, performance and behaviour. PhD thesis. Swedish University of Agricultural Sciences, Faculty of Natural Resources, Department of Food Science, Uppsala, Sweden.

Brunius, C.; Zamaratskaia, G.; Andersson, K.; Chen, G.; Norrby, M.; Madej, A. and Lundström, K. 2011. Early immunocastration of male pigs with Improvac $^{\circledR}$ - Effect on boar taint, hormones and reproductive organs. Vaccine 29:9514-9520. https://doi.org/10.1016/j.vaccine.2011.10.014

Čandek-Potokar, M.; Prevolnik, M. and Škrlep, M. 2014. Testes weight is not a reliable tool for discriminating immunocastrates from entire males. p.43-49. In: Proceedings of the International Symposium of Animal Science. Faculty of Agriculture, Belgrade, Serbia.

Čandek-Potokar, M.; Škrlep, M. and Zamaratskaia, G. 2017. Immunocastration as alternative to surgical castration in pigs. p.109-126. In: Theriogenology. Carreira, R. P., ed. IntechOpen, Rijeka. 
Doran, E.; Whittington, F. W.; Wood, J. D and McGivan J. D. 2002. Cytochrome P450IIE1 (CYP2E1) is induced by skatole and this induction is blocked by androstenone in isolated pig hepatocytes. Chemico-Biological Interactions 140:81-92. https://doi.org/10.1016/S0009-2797(02)00015-7

Font-i-Furnols, M.; Carabús, A.; Muñoz, I.; Čandek-Potokar, M. and Gispert, M. 2016. Evolution of testes characteristics in entire and immunocastrated male pigs from 30 to $120 \mathrm{~kg}$ live weight as assessed by computed tomography with perspective on boar taint. Meat Science 116:8-15. https://doi.org/10.1016/j.meatsci.2016.01.008

Gispert, M.; Àngels Oliver, M.; Velarde, A.; Suarez, P.; Pérez, J. and Font i Furnols, M. 2010. Carcass and meat quality characteristics of immunocastrated male, surgically castrated male, entire male and female pigs. Meat Science 85:664-670. https://doi.org/10.1016/j.meatsci.2010.03.021

Große-Brinkhaus, C.; Storck, L. C.; Frieden, L.; Neuhoff, C.; Schellander, K.; Looft, C. and Tholen, E. 2015. Genome-wide association analyses for boar taint components and testicular traits revealed regions having pleiotropic effects. BMC Genetics 16:36. https://doi.org/10.1186/s12863-015-0194-z

Hernández-García, F. I.; Izquierdo, M.; Del Rosario, A. I.; Montero, A.; Pérez, M. A.; García-Gudiño, J. and Garrido, N. 2018. Adaptation of immunocastration treatment to montanera system for male Iberian pigs: effects on reproductive organs and carcass traits. Arch. Zootec. Proceedings IX Simposio Internacional sobre el Cerdo Mediterráneo. p.97-100.

Hernández-García, F. I.; Duarte, J. L.; Pérez, M. A.; Raboso, C.; Del Rosario, A. I. and Izquierdo, M. 2013. Successful long-term pre-pubertal immunocastration of purebred Iberian gilts reared in extensive systems. 8th International Congress on Mediterranean Pig, Ljubljana (Slovenia), October 2013. Acta Agriculturae Slovenica Supplement 4:123-126.

Herring, C. M.; Bazer, F. W.; Johnson, G. A. and Wu, G. 2018. Impacts of maternal dietary protein intake on fetal survival, growth, and development. Experimental Biology and Medicine 243:525-533.

Hughes, P. E. and Varley, M. A. 1980. Reproduction in pigs. Buttherworth-Heinemann Ltd, London.

Jacyno, E.; Kawezcka, M.; Pietruszka, A. and Sosnowska, A. 2015. Phenotypic correlations of testes size with semen traits and the productive traits of young boars. Reproduction in Domestic Animals 50:926-930. https://doi. org/10.1111/rda.12610

Lugar, D. W.; Rhoads, M. L.; Clark-Deener, S. G.; Callahan, S. R.; Revercomb, A. K.; Prusa, K. J. and Estienne, M. J. 2017. Immunological castration temporarily reduces testis size and function without long-term effects on libido and sperm quality in boars. Animal 11:643-649. https://doi.org/10.1017/S1751731116002081

Park, W. J.; Park, B. J.; Song, Y. J.; Lee, J. B.; Park, S. Y.; Song, C. S.; Lee, S. W.; Jang, Y. G.; Kim, H. M.; Han, J. H.; Jung, C. H. and Choi, I. S. 2015. Induction of immunocastration in pre-pubertal boars immunized with recombinant gonadotropin-releasing hormone conjugated with Salmonella Typhimurium flagellin fljB. Japanese Journal of Veterinary Research 63:73-81.

Sikarwar, S.; Mathur, R.; Joshi, S.; Thanvi, P. and Dangi, A. 2018. Gross and morphometrical studies on the testes of Large White Yorkshire pig (Sus scrofa). Journal of Animal Research 8:709-712.

Škrlep, M.; Šegula, B.; Zajec, M.; Kastelic, M.; Košorok, S.; Fazarinc, G. and Čandek-Potokar, M. 2010. Effect of immunocastration $\left(\right.$ Improvac $^{\circledR}$ ) in fattening pigs I: Growth performance, reproductive organs and malodorous compounds. Slovenian Veterinary Research 47:57-64.

Škrlep, M.; Batorek, N.; Bonneau, M.; Prevolnik, M.; Kubale, V. and Čandek-Potokar, M. 2012. Effect of immunocastration in group-housed commercial fattening pigs on reproductive organs, malodorous compounds, carcass and meat quality. Czech Journal of Animal Science 57:290-299. https://doi.org/10.17221/5964-CJAS

Teankum, K.; Tummaruk, P.; Kesdangsakonwut, S.; Antarasena, T.; Lacharoj, S.; Singlor, J.; Kunavongkrit, A. and Thanawongnuwech, R. 2013. Testicular atrophy and its related changes in culled boars: A pathological investigation. Thai Journal of Veterinary Medicine 43:511-518.

Zamaratskaia, G. and Rasmussen, M. K. 2015. Immunocastration of male pigs - situation today. Procedia Food Science 5:324-327. https://doi.org/10.1016/j.profoo.2015.09.064 